\title{
Feasibility of implementing a behavioral economics mobile health platform for individuals with behavioral health conditions
}

\author{
Barry Granek ${ }^{1} \cdot$ Aja Evans ${ }^{1} \cdot$ Jorge Petit ${ }^{1} \cdot$ Mary Crawford James ${ }^{2}$ - $\cdot$ Yixuan (Matt) Ma ${ }^{3} \cdot$ Matthew Loper $^{3}$. \\ Michael Fuccillo ${ }^{3}$. Rudy Schmidt ${ }^{3}$
}

Received: 21 July 2020 / Accepted: 8 October 2020 / Published online: 25 February 2021

(c) The Author(s) 2021

\begin{abstract}
Coordinated Behavioral Care's (CBC) Pathway Home $\mathrm{TM}^{\mathrm{TM}}(\mathrm{PH})$ program partnered with Wellth, Inc., a mobile health platform grounded in behavioral economics theory, to help individuals with behavioral health conditions build and reinforce health habits by providing daily reminders to take medication, requiring tasks (photos demonstrating remembrance), and providing financial incentives tied to behaviors. CBC made Wellth, Inc. available to individuals enrolling in its PH program for the purpose of demonstrating the feasibility of implementing a novel mobile technology grounded in behavioral economic theory to increase habits of health activities, such as taking medication, among adults with behavioral health conditions.
\end{abstract}

Keywords Behavioral health $\cdot$ Behavioral economics $\cdot$ Health technology $\cdot$ Financial incentives $\cdot$ Care transitions

\section{Introduction}

Coordinated Behavioral Care's (CBC) Pathway Home ${ }^{\mathrm{TM}}$ $(\mathrm{PH})$ is an innovative program that facilitates care transitions and community reintegration after an inpatient stay by cultivating independent living skills and connection to community resources and supports Wellth. Pathway Home ${ }^{\mathrm{TM}}$ is community-based and time limited, lasting up to nine months following a care transition into the community. The Pathway Home ${ }^{\mathrm{TM}}$ approach is organized around four distinct phases with a focused set of tasks. For example, tasks may include accompanying home upon hospital discharge, accompaniment to appointments, medication reconciliation, and providing reminders for healthcare activities. Over the course of the program, individuals in Pathway Home $^{\mathrm{TM}}$ gradually become more autonomous, self-directed, and responsible for their own care. Employing a multidisciplinary team of licensed clinicians, nurses, peers, and care

Barry Granek

bgranek@CBCare.org

1 Coordinated Behavioral Care, 55 Broadway, Suite 701, New York, NY 10006, USA

2 Concert Health, San Diego, CA, USA

3 Wellth Inc, Long Island City, NY, USA managers, Pathway Home ${ }^{\mathrm{TM}}$ staff incorporate a variety of techniques and activities that ensures healthcare tasks are completed and individuals are assuming a more active role in their own care. Pathway Home ${ }^{\mathrm{TM}}$ has piloted and incorporated technology-assisted care (TAC) solutions [1] including Wellth, a mobile application that combines behavioral economics and mobile technology to assist in keeping track of health activities and the building of lasting habits.

Individuals who undergo lengthy inpatient stays in psychiatric hospitals, or other institutional settings where healthcare activities are managed by an inpatient team, receive aftercare plans when they transition to the community. These aftercare plans are often complex and require robust follow up, as the habits needed to manage one's own health may need to be relearned. Without building the habits necessary for recovery activities, such as taking medications, these individuals are at risk for hospital readmission, adverse health events, unnecessary healthcare costs, and reduction in quality of life.

\subsection{Extent of the problem}

Studies have shown that $43 \%$ of individuals living with a behavioral health condition report not taking their medication [2]. Approximately $40 \%$ stop taking their medication within one year from being prescribed, and $75 \%$ stop within two years [2]. It is also common for individuals to take their 
medications irregularly over long periods of time. There are known risks to individuals when they cease or miss doses of their medication; for example, individuals with a behavioral health condition that do not take their prescribed psychotropic medications are 3.7 times more likely to experience symptom relapse than those who take their medication [3]. Interventions are needed to assist individuals with behavioral health conditions in habit development and building the skill set needed to effectively manage one's own healthcare, such as following a medication regimen.

\subsection{Behavioral economics and financial incentives}

$\mathrm{CBC}$ has been interested in the use of behavioral economics and related technology interventions to impact health behaviors for the populations served by the Pathway Home ${ }^{\text {TM }}$ teams. Behavioral economics leverages psychology and economics to explain why individuals make seemingly less than optimal decisions, such as performing unhealthy behaviors (e.g., eating unhealthy food) or not performing healthy behaviors (e.g., not taking one's prescribed medications) [4-6]. These suboptimal decisions can be explained by the concepts of the intention behavior gap and present bias. The intention behavior gap is the concept whereby individuals develop the intention to perform a behavior, but they do not complete the behavior (i.e. they did not cross the gap) [6]. Present bias relates to an individuals' tendency to overemphasize present benefits compared to future harms, or vice versa [6]. For example, if an individual has the choice between consuming a candy bar versus taking a medication, consuming the candy bar would provide a significantly higher level of present value compared to the pill, even though not taking the medication might be detrimental to their health in the future.

One promising behavioral economics intervention and strategy implemented to overcome the intention behavior gap and present bias is to offer individuals targeted financial incentives that reward verifiable participation in their prescribed medication regimen(s) and/or treatment plan(s). For example, financial incentives of just a few dollars per day have been used to help individuals with a behavioral health condition and/or chronic, co-morbid diagnosis follow a medication regimen, producing odds that are seven (7) times higher of individuals taking their medication [7, 8]. In a cluster randomized controlled trial, individuals with schizophrenia were offered financial incentives over the course of one year to improve observance of taking an antipsychotic. Results from the intervention group demonstrated an $11.5 \%$ increase in following one's medication regimen and improved overall ratings on subjective quality of life metrics [9]. Moreover, a robust body of research demonstrates that incentives are most effective when coupled as closely as possible with the behavior being reinforced, as delays between the delivery of the incentive and the performance of the desired behavior are less effective in driving sustained behavioral change [10]. Incentives designed to reinforce these daily behaviors further routinize medication self-management and bring about long-term behavioral change that result in sustained long-term habit formation $[8,11,12]$.

\section{Methods}

\subsection{Intervention: The Wellth mobile application}

The Wellth mobile application combines behavioral economics and financial incentives to aid with healthcare activities. Individuals who struggle to self-manage their medication(s) and/or treatment tasks can benefit from a technology assisted care (TAC) solution like Wellth [13]. According to Rathbone and Prescott, TAC solutions may serve multiple purposes, such as facilitating engagement in healthy behaviors, providing access to care, reducing utilization costs, and improving quality of care [14]. Additionally, TAC solutions encourage and empower individuals to be active participants in their own healthcare and treatment [14-17].

To evaluate whether a TAC solution can be successfully utilized/implemented by care teams providing care transition services, CBC partnered with Wellth in July 2018 to offer this technology to individuals enrolled in the Pathway Home $^{\mathrm{TM}}$ program. PH participants were assessed as candidates for Wellth based on three inclusion criteria: risk for not taking medication, history of not taking medications, and ability to use mobile technology or ability to be taught to use mobile technology.

In order to launch Wellth with the Pathway Home ${ }^{\mathrm{TM}}$ teams, CBC worked with Wellth to organize a training for Pathway Home ${ }^{\mathrm{TM}}$ staff on how to enroll and teach Pathway Home ${ }^{\mathrm{TM}}$ participants to use the Wellth mobile application. Each team chose a Wellth Champion, who would manage enrolling and onboarding new participants onto the platform. The teams were instructed to first ask each eligible participant whether they would be interested in using the application. If interested, the Wellth Champion would move forward with downloading the application, training the participant on how the application worked, and assisting in completing a demonstration task. From there, each participant would begin using the application on the designated start date, with the intervention lasting 90 days. The teams worked to onboard each participant to the application as close to hospital discharge or community transition as possible. Ongoing collaboration occurred between Pathway Home $^{\mathrm{TM}}$ and Wellth throughout the partnership in order to troubleshoot any problems or concerns, ensuring everyone 
understood the use of the technology, enrollment of participants, and mitigation of any enrollment barriers.

\subsection{Application design and implementation}

Eligible Pathway Home ${ }^{\mathrm{TM}}$ participants who agreed to enroll were initially instructed to download the Wellth mobile application onto their respective mobile device(s). The program participants provided consent prior to beginning to use Wellth. Additionally, when the participants downloaded Wellth and logged in, they had to accept Wellth terms and conditions via the app by checking the boxes on that page of the app. For those without smart phone access, Pathway Home ${ }^{\mathrm{TM}}$ supplied a lender smart-phone to Pathway Home ${ }^{\mathrm{TM}}$ participants for 90-days, so all eligible and interested Pathway Home ${ }^{\mathrm{TM}}$ participants could be offered Wellth. Subsequently, Pathway Home ${ }^{\mathrm{TM}}$ teams explained to each Wellth participant that the program would last 90 days, and that each member would be eligible to receive up to $\$ 30$ a month, for a potential total of $\$ 90$ over the course of the 90-day program. Each day, participants received reminders via the application at preset times tailored to the participant instructing them to "check-in" by submitting a photo of their medication via the application. The behavior of submitting a photo of their medication requires the participant to put their medication in their hand, which helps them to cross the intention-behavior gap and actually perform the behavior of taking the medication. After submission of the photo, participants received instant reward messaging in order to tie the behavior as closely to the incentives as possible. This instant reward messaging stated that the action was complete and updated the participant on the money they received for completing their daily task. An example of such reward message is "All done, you kept $\$ 2.00$ for today!". This creates present value for the healthy behavior and overcomes present bias. To maximize the behavioral impact of these financial incentives, the Wellth mobile application and reward messaging frame the incentives using loss aversion, a concept rooted in behavioral economics research, which suggests that the threat of loss is a more powerful motivator than the chance of an equivalent gain $[4,18]$. Participants were shown that they have $\$ 30$ in their Wellth Rewards account at the beginning of each month. As long as they submitted their photo check-ins via the Wellth mobile application every day, they avoided the loss of $\$ 2$ for that day from their $\$ 30$ balance. If participants missed 15 or more days during the month, they received no rewards. Rewards were provided on a monthly basis via a reloadable rewards card. These rewards cards were redeemable for a wide variety of products and services but were restricted to prevent participants from purchasing "unhealthy" products and services (alcohol, tobacco, firearms, lotteries, etc.). See Fig. 1 for screens detailing the mobile application experience for a participant.

\section{Findings}

In this retroactive study, data was analyzed for program participants who utilized Wellth from July 2018 to July 2019. Participation in Wellth was voluntary and participants were instructed they could opt out at any time. Data analysis was retroactive, post data collection and program implementation. Overall, 53 participants were successfully enrolled into the program. The average age of participants was 40 years old, with a standard deviation of 16 years. The youngest participant was 19 years old, and the oldest participant was 78 years old. $60 \%$ of participants identified as Male and $40 \%$ of participants identified as Female. All participants had a Primary Behavioral Health Diagnosis (Table 1).

Medication check-in rate for each program participant was determined by dividing the number of actual care plan task check-ins submitted via the Wellth mobile application by the amount of total possible check-ins throughout the 90-day program window for each program participant. 35 out of 53 participants (66\%) demonstrated a check-in rate greater than $70 \%$ (Table 1). 19 out of 53 participants (34\%) demonstrated a check-in rate less than or equal to $70 \%$. Medication check-in rate for all program participants in aggregate was determined by dividing the total number of care plan task check-ins submitted via the Wellth mobile application from the 53 participants $(5,498$ check-ins submitted) by the amount of total possible check-ins throughout the 90-day program window (6,345 distinct Wellth check-in tasks in total). The aggregate medication check-in rate for all 53 participants was $87 \%$.

Overall, a total of 53 participants enrolled who have since ended their program. 29 of the 53 participants (54.72\%) fully completed the 90 days, indicated as "Program Complete" in the data (Table 1). 12 of the 52 (22.64\%) participants ended their program because Wellth could not obtain contact with them for a period of 21 days or greater while they were enrolled in the program, indicated as "Program Complete Dropped out Involuntarily" in the data. 12 of the 52 (22.64\%) participants ended their program because they did not want to participate any longer before their 90 days were up, indicated as "Program Complete Dropped out Voluntarily" in the data.

Wellth included a feature which asked Pathway Home ${ }^{\mathrm{TM}}$ participants for feedback on their experiences through a variety of questions about Wellth. Most participants liked "the reminders" when asked what they liked most about Wellth. Two-thirds of participants stated the financial rewards motivated them to take their medications and stick to their care plan more than before, with one-third stating they experienced no change. Participants averaged 9.3 on a scale of 1-10 when asked how likely they were to refer a family member or someone else to Wellth. To the question, "On 

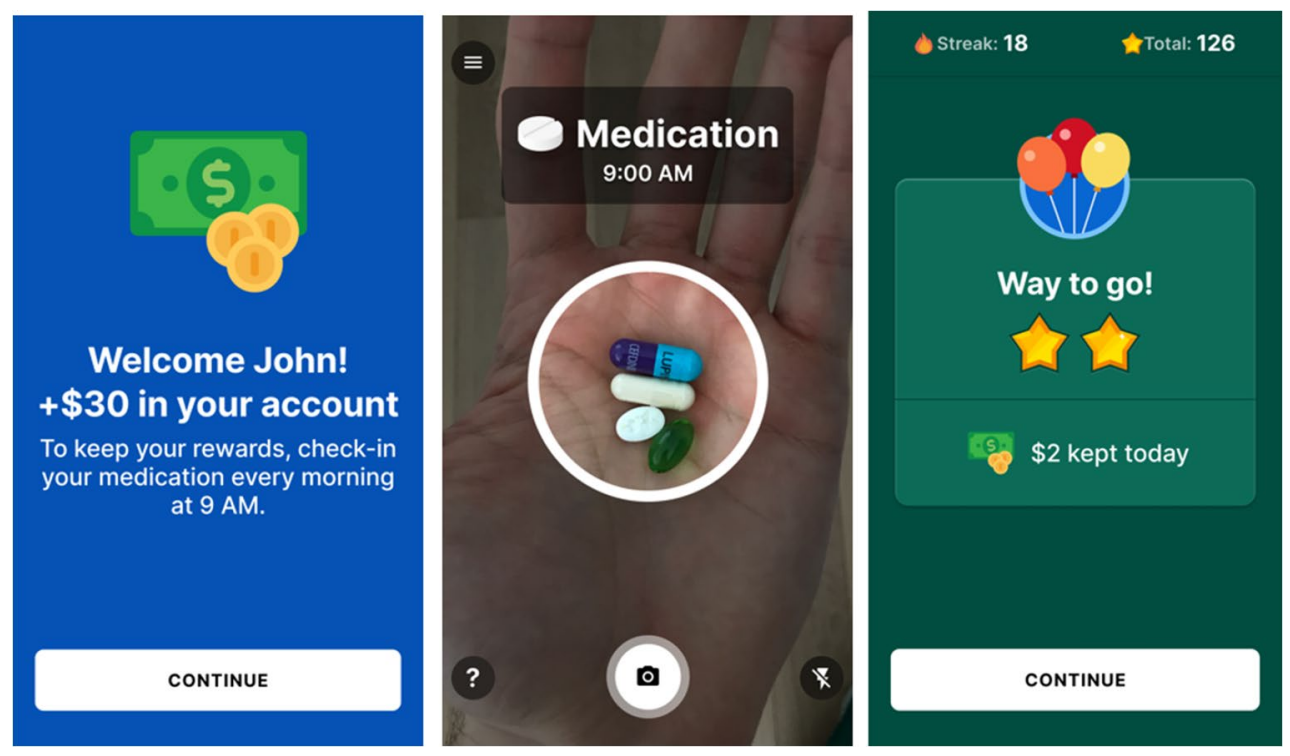

Fig. 1 Screenshots of the mobile application experience for each participant in order to submit photos of their daily tasks and the reward messaging accompanying this behavior

Table 1 Characteristics of Wellth ${ }^{\mathrm{TM}}$ program participants

\begin{tabular}{|c|c|}
\hline Variables & Statistics \\
\hline Total participants (\%) & $53(100 \%)$ \\
\hline \multicolumn{2}{|l|}{ Gender $(\%)$} \\
\hline Male & $32(60 \%)$ \\
\hline Female & $21(40 \%)$ \\
\hline Mean Age (SD) & $40(16)$ \\
\hline \multicolumn{2}{|l|}{ Primary Behavioral Health Diagnosis (\%) } \\
\hline Bipolar and related disorders & $8(15 \%)$ \\
\hline Depressive disorders & $5(9 \%)$ \\
\hline Trauma and stressor-related disorders & $1(2 \%)$ \\
\hline $\begin{array}{l}\text { Schizophrenia spectrum and other psychotic disor- } \\
\text { ders }\end{array}$ & $39(74 \%)$ \\
\hline \multicolumn{2}{|l|}{ Wellth $^{\mathrm{TM}}$ Program Check-in Rate (\%) } \\
\hline Less than or equal to $70 \%$ & $18(34 \%)$ \\
\hline Greater than $70 \%$ & $35(66 \%)$ \\
\hline \multicolumn{2}{|l|}{ Program Completion Status (\%) } \\
\hline Completed program & $29(54.7 \%)$ \\
\hline Dropped out involuntarily & $12(22.6 \%)$ \\
\hline Dropped out voluntarily & $12(22.6 \%)$ \\
\hline
\end{tabular}

a scale of $0-5$, how important was the size of the financial rewards in your decision to enroll in the Wellth program?" the average response was 4.7.

A survey was also sent to Pathway Home ${ }^{\mathrm{TM}}$ staff, who shared feedback that was optimistic and positive. On whether to use the program longer term, one staff shared "having an incentive based program produced positive outcomes and encourages participants early on how to be accountable towards their treatment." Commenting on ease of use, one staff said "Wellth is effective for those who are not 'foreign' to utilizing a smart phone. Once educated on how the app works, most participants find it manageable."

\section{Discussion}

Fifty-three Pathway Home ${ }^{\mathrm{TM}}$ program participants enrolled in Wellth, all of whom had transitioned from a lengthy inpatient stay at a psychiatric hospital or other institutional setting, putting them at higher risk for hospital readmission, adverse health events, unnecessary healthcare costs, and reduction in quality of life when they reintegrated into the community. With all these factors combined, the data indicates that the CBC Pathway Home $^{\mathrm{TM}}$ and the Wellth mobile application can be successfully implemented with high-risk participants with behavioral health conditions. This required careful design from a behavioral economic, care transition, and product development perspective in order to create a program that is easy to implement, person-centered, and effective in leveraging behavioral economic principles, such as financial incentives to drive better health outcomes.

This program completion rate of approximately 55\% was particularly compelling, given the complex needs of those living with a behavioral health condition. Moreover, the aggregate check-in rate was substantially higher than what is typically seen in this population (the overall incidence of individuals reporting not taking medication is 43\%) [2]. Program participants had an aggregate check-in 
rate of $87 \%$, indicating that they did not check-in only $13 \%$ of the time. While check-in is only an indication that medication was taken, not proof, the difference of $13 \%$ from the $43 \%$ is a compelling improvement of $30 \%$.

The findings should be interpreted in light of their limitations. This was not a randomized controlled trial with Wellth and control group(s), and included a small number of participants, which affects the key insights and findings gleaned from the program results to date. Moreover, while multiple indices were included (Wellth received check-in data for each program participant daily), additional pre-program data would further supplement the program results and be helpful in evaluating the Wellth program's impact on participant utilization rates. The authors acknowledge that motivation is one potential reason for not taking medication and that other reasons likely exist.

Finally, we recognize that the use of incentives to facilitate care plan completion may be regarded as nonconventional and, in certain circumstances, coercive. Likewise, the program's methodology whereby individuals would lose rewards for each failed check-in day may be perceived as 'penalizing'. While these are important factors to consider prior to large-scale implementation of this type of program, behavioral economics research strongly suggests that most individuals have difficulty making decisions in the short-term that are aligned with their long-term interests [19]. To overcome this barrier, financial incentives play a key role in realigning ingrained behavior patterns in a manner that best promotes improved care plan completion and better overall health outcomes. In this light, the risk associated with offering incentives to populations with behavioral health conditions are outweighed by the potential rewards.

\section{Implications for behavioral health}

The partnership between CBC and Wellth has assisted Pathway Home ${ }^{\mathrm{TM}}$ participants in building healthier habits. The use of daily reminders and financial incentives appeared to reinforce and promote the habit of taking one's medication. This partnership is encouraging as it indicates that program participants are interested in using novel ways to address healthcare issues. It has shown that there is a willingness to try emerging technologies, even if there is a risk of failure or potential inability to successfully learn or integrate into one's day-to-day schedule. With a completion rate of approximately $55 \%$, the utilization of Wellth demonstrates the feasibility of a care management program implementing a novel technology solution.

In this ever-changing healthcare environment, with a host of emerging technology assisted care solutions,
CBC's Pathway Home ${ }^{\mathrm{TM}}$ has initiated piloting new technologies. While there are limitations to the findings of this intervention, targeted financial incentives delivered using Wellth mobile application show promising signs of facilitating the development of habit formation for health activities, like taking medication, in populations with behavioral health conditions, as well as promoting healthy behaviors.

Authors' contributions All authors contributed to study conception and design. Material preparation, data collection and analysis were performed by Barry Granek, Aja Evans, Yixuan (Matt) Ma, Michael Fuccillo, and Rudy Schmidt. All authors reviewed previous versions of the manuscript and approved final manuscript.

Funding Yixuan (Matt) Ma, Matthew Loper, Michael Fuccillo, and Rudy Schmidt are affiliated with Wellth Inc.. Coordinated Behavioral Care is a paying customer of Wellth Inc.

\section{Compliance with ethical standards}

Conflicts of interest None to declare.

Open Access This article is licensed under a Creative Commons Attribution 4.0 International License, which permits use, sharing, adaptation, distribution and reproduction in any medium or format, as long as you give appropriate credit to the original author(s) and the source, provide a link to the Creative Commons licence, and indicate if changes were made. The images or other third party material in this article are included in the article's Creative Commons licence, unless indicated otherwise in a credit line to the material. If material is not included in the article's Creative Commons licence and your intended use is not permitted by statutory regulation or exceeds the permitted use, you will need to obtain permission directly from the copyright holder. To view a copy of this licence, visit http://creativecommons.org/licenses/by/4.0/.

\section{References}

1. Petit, J. \& Granek, B. Virtual Pathway to Technology-Assisted Care Models: Keeping Up with New Technology in Behavioral Health Care. Behavioral Health News, 2018;5(4):22.https:// behavioralhealthnews.org/a-virtual-pathway-to-technologyassisted-care-models-keeping-up-with-new-technology-inbehavioral-health-care/. Accessed December 10, 2019.

2. Lucca JM, Ramesh M, Parthasarathi G, et al. Incidence and factors associated with medication nonadherence in patients with mental illness: a cross-sectional study. J Postgrad Med. 2015;61(4):251-6. https://doi.org/10.4103/0022-3859.166514.

3. Townsend L, Floersch J, Findling RL. Adolescent attitudes toward psychiatric medication: the utility of the drug attitude inventory. J Child Psychol Psychiatry. 2009;50(12):1523-31. https://doi.org/10.1111/j.1469-7610.2009.02113.

4. Kahneman D. Maps of bounded rationality: psychology for behavioral economics. Am Econ Rev. 2003;93(5):1449-75.

5. Loewenstein G, Brennan T, Volpp KG. Asymmetric paternalism to improve health behaviors. JAMA. 2007;298(20):2415-7. 
6. Chang LL, DeVore AD, Granger BB, et al. Leveraging behavioral economics to improve heart failure care and outcomes. Circulation. 2017;136(8):765-72.

7. Haff N, Patel MS, Lim R, et al. The role of behavioral economic incentive design and demographic characteristics in financial incentive-based approaches to changing health behaviors: a metaanalysis. Am J Health Promot. 2015;29(5):314-23.

8. Priebe S, Sinclair J, Burton A, et al. Acceptability of offering financial incentives to achieve medication adherence in patients with severe mental illness: a focus group study. J Med Ethics. 2010;36:463-8.

9. Priebe S, Bremner SA, Lauber C, et al. Financial incentives to improve adherence to antipsychotic maintenance medication in non-adherent patients: a cluster randomized controlled trial. Natl Inst Health Res. 2016;20(70):1-150.

10. Blumenthal KJ, Saulsgiver KA, Norton L, et al. Medicaid incentive programs to encourage healthy behavior show mixed results to date and should be studied and improved. Health Aff. 2013;32(3):497-507.

11. Sen AP, Sewell TB, Riley EB, et al. Financial incentives for homebased health monitoring: a randomized controlled trial. J Gen Intern Med. 2014;29(5):770-7.

12. Petry NM, Alessi SM, Byrne S, et al. Reinforcing adherence to antihypertensive medications. J Clin Hypertens. 2015;17(1):33-8. https://www.ncbi.nlm.nih.gov/pmc/articles/PMC4293311/. Accessed December 10, 2019.

13. Sibeko $\mathrm{G}$, Temmingh $\mathrm{H}$, Mall $\mathrm{S}$, et al. Improving adherence in mental health service users with severe mental illness in South Africa: a pilot randomized controlled trial of a treatment partner and text message intervention vs. treatment as usual. BioMed Central. 2017;10(584):1-8.

14. Rathbone AL, Prescott J. The use of mobile apps and SMS messaging as physical and mental health interventions: systematic review. J Med Internet Res. 2017;19(8):295th ser (1 13).

15. Petit J, Pierce J, Kohl-Grant E et al. Behavioral Health and Emerging Technologies. Coordinated Behavioral Care Whitepaper, 2019. Available at:http://www.cbcare.org/wp-content/uploads/ 2019/09/Behavioral-Health-Emerging-Technologies-White-PaperSeptember-2019-1.pdf. Accessed February 3, 2021.

16. Moller AC, Merchant G, Conroy DE, et al. Applying and advancing behavior change theories and techniques in the context of a digital health revolution: proposals for more effectively realizing untapped potential. J Behav Med. 2017;40(1):85-98.

17. Becker S, Kribben A, Meister S, et al. User profiles of a smartphone application to support drug adherence - experiences from the iNephro Project. PLoS One. 2013;8(10):1-6.

18. Kahneman D, Knetsch JL, Thaler RH. Anomalies: the endowment effect, loss aversion, and status quo bias. J Econ Perspect. 1991;5(1):193-206.

19. Kahneman D. Thinking, fast and slow. New York: Farrar, Straus and Giroux; 2011.

Publisher's note Springer Nature remains neutral with regard to jurisdictional claims in published maps and institutional affiliations. 